\title{
Primary repair: damage control surgery in esophageal trauma
}

\section{El reparo primario: el control de daños en el trauma de esófago}

\author{
Mauricio Millán, ${ }^{1,2}$ Michael W. Parra, ${ }^{3}$ (D) Boris Sanchez-Restrepo, 4 (D) Yaset Caicedo, ${ }^{5}$ (D) Carlos \\ Serna, ${ }^{4}$ (D) Adolfo González-Hadad, ${ }^{4,6,7}$ (D) Luis Fernando Pino, ${ }^{4,7}$ Mario Alain Herrera, ${ }^{4,7}$ (D) \\ Fabian Hernández, ${ }^{4,7}$ Fernando Rodríguez-Holguín, ${ }^{5}$ (D) Alexander Salcedo, 2,4,7,8 (iD) José Julián \\ Serna, ${ }^{2,4,7,8}$ Alberto García, ${ }^{2,4,8}$ iD Carlos A. Ordoñez ${ }^{2,4,8}$ (D) \\ ordonezcarlosa@gmail.com, carlos.ordonez@fvl.org.co
}

1 Fundación Valle del Lili, Department of Surgery, Division of Transplant Surgery, Cali, Colombia, 2 Universidad Icesi, Cali, Colombia. , 3 Broward General Level I Trauma Center, Department of Trauma Critical Care, Fort Lauderdale, FL - USA, 4 Universidad del Valle, Facultad de Salud, Escuela de Medicina, Department of Surgery, Division of Trauma and Acute Care Surgery, Cali, Colombia., 5 Fundación Valle del Lili, Centro de Investigaciones Clínicas (CIC), Cali, Colombia 6 Centro Médico Imbanaco, Cali, Colombia. , 7 Hospital Universitario del Valle, Department of Surgery, Division of Trauma and Acute Care Surgery, Cali, Colombia., 8 Fundación Valle del Lili, Department of Surgery, Division of Trauma and Acute Care Surgery, Cali, Colombia.,

\section{Abstract}

Esophageal trauma is a rare but life-threatening event associated with high morbidity and mortality. An inadvertent esophageal perforation can rapidly contaminate the neck, mediastinum, pleural space, or abdominal cavity, resulting in sepsis or septic shock. Higher complications and mortality rates are commonly associated with adjacent organ injuries and/or delays in diagnosis or definitive management. This article aims to delineate the experience obtained by the Trauma and Emergency Surgery Group (CTE) of Cali, Colombia, on the surgical management of esophageal trauma following damage control principles. Esophageal injuries should always be suspected in thoracoabdominal or cervical trauma when the trajectory or mechanism suggests so. Hemodynamically stable patients should be radiologically evaluated before a surgical correction, ideally with computed tomography of the neck, chest, and abdomen. While hemodynamically unstable patients should be immediately transferred to the operating room for direct surgical control. A primary repair is the surgical management of choice in all esophageal injuries, along with endoscopic nasogastric tube placement and immediate postoperative care in the intensive care unit. We propose an easy-to-follow surgical management algorithm that sticks to the philosophy of "Less is Better" by avoiding esophagostomas.

Palabras clave:

Estenosis esofágica, cuidados de soporte vital avanzado para traumatismos, laparotomía, funduplicatura, tratamiento de heridas con presión negativa, trastornos de la deglución, enfisema mediastínico, toracotomía, fístula traqueoesofágica, esófago.

Esophageal stenosis, advanced fundoplication, negative-pressure emphysema, thoracotomy, tracheoesophageal fistula, esophagus. 
Copyright: @ 2021 Universidad del Valle (c) (1) $(5)$

Conflicts of interest:

The authors declare that they have no conflict of interest.

\section{Acknowledgments}

We would like to extend our gratitude to the anatomical illustrator Fabian $\mathrm{R}$. Cabrera P., Professor of the Design Department of the Integrated Arts Faculty, for the illustrations and cover design. We acknowledge to Natalia Padilla and Linda M. Gallego for your contributions in the drafting of this manuscript.

\section{Corresponding author:}

Carlos A. Ordonez, MD, FACS. Division of Trauma and Acute Care Surgery, Department of Surgery. Fundación Valle del Lili. Cali, Colombia; Division of Trauma and Acute Care Surgery, Department of Surgery, Universidad del Valle, Cali, Colombia; Universidad Icesi, Cali, Colombia. Email: ordonezcarlosa@gmail.com, carlos.ordonez@fvl.org.co

\section{Resumen}

El trauma esofágico es un evento poco frecuente pero potencialmente mortal. Una perforación esofágica inadvertida puede ocasionar la rápida contaminación del cuello, el mediastino, el espacio pleural o la cavidad abdominal, lo cual puede resultar en sepsis o choque séptico. Las complicaciones y la mortalidad aumentan con el retraso en el diagnóstico o manejo definitivo, y la presencia de lesiones asociadas. El objetivo del presente artículo es describir la experiencia adquirida por el grupo de cirugía de Trauma y Emergencias (CTE) de Cali, Colombia en el manejo del trauma de esófago de acuerdo con los principios de la cirugía de control de daños. Las lesiones esofágicas deben sospecharse en todo trauma toraco-abdominal o cervical en el que el mecanismo o la trayectoria de la lesión lo sugieran. El paciente hemodinámicamente estable se debe estudiar con imágenes diagnósticas antes de la corrección quirúrgica del defecto, idealmente por medio de tomografía computarizada del cuello, tórax y abdomen con contraste endovenoso. Mientras que en el paciente hemodinámicamente inestable se debe explorar y controlar la lesión. El reparo primario es el manejo quirúrgico de elección, con la previa colocación de una sonda nasogástrica y el seguimiento postoperatorio estricto en la unidad de cuidado intensivo. Se propone un algoritmo de manejo quirúrgico que resulta fácil de seguir y adopta la premisa "Menos es Mejor" evitando realizar derivaciones esofágicas.

\section{Remark}

\section{1) Why was this study conducted?}

Thoracic trauma with the involvement of the great vessels is a surgical challenge due to the complex and restricted anatomy of these structures and its association with adjacent organ damage. The aim of this article is to delineate the experience obtained in the surgical management of thoracic vascular injuries via the creation of a practical algorithm that includes basic principles of damage control surgery.

\section{2) What were the most relevant results of the study?}

Early application of a resuscitative median sternotomy together with a zone 1 resuscitative endovascular balloon occlusion of the aorta (REBOA) in hemodynamically unstable patients with thoracic outlet vascular injuries improves survival by providing rapid stabilization of central aortic pressure and serving as a bridge to hemorrhage control. Damage control surgery principles should also be implemented when indicated followed by definitive repair once the correction of the lethal diamond has been achieved.

\section{3) What do these results contribute?}

We have developed an easy to follow six-step management algorithm that clearly illustrates the surgical care of patients with thoracic outlet vascular injuries. 


\section{Introduction}

Esophageal trauma is a relatively uncommon but challenging clinical finding with a high associated morbi-mortality ${ }^{1}$. An unrecognized esophageal perforation can evolve to an infection of the neck, mediastinum, pleural space, and/or abdomen, which in turn could lead to sepsis and shock ${ }^{2,3}$. The organ is vulnerable to perforation due to its thin wall, the lack of a supporting adventitia, and the relatively poor blood supply ${ }^{4,5}$. Higher complications and mortality rates are commonly associated with adjacent organ injuries and/or delays in diagnosis or definitive management ${ }^{6,7}$. This article aims to delineate the experience on the surgical management of esophageal trauma via applying basic principles of damage control surgery obtained by the Trauma and Emergency Surgery Group (CTE) of Cali, Colombia which is made up of experts from the Hospital Universitario del Valle "Evaristo García", the Hospital Universitario Fundación Valle del Lili, the Universidad del Valle and Universidad Icesi, and the collaboration of the Asociación Colombiana de Cirugía, the Pan-American Trauma Society and of national and international specialists.

\section{Epidemiology}

Esophageal injuries are rare, life-threatening events with a high overall reported mortality, especially in penetrating injuries in which it has been reported between $29-44 \%{ }^{7}$. Penetrating trauma is the most common mechanism of injury, and the most prevalent injured segment is the cervical followed by the intra-thoracic ${ }^{7,8}$. High-speed motor vehicle accidents are the main cause of blunt esophageal trauma, in which the horizontal deceleration produces compression of the esophagus against the vertebral bodies ${ }^{7,9}$.

Asensio et al., found that $99(24.0 \%)$ patients had a systolic blood pressure of less than $90 \mathrm{~mm}$ $\mathrm{Hg}$ and a median injury severity score (ISS) of 28 (range, 4 -75) in a series of 405 patients with penetrating esophageal trauma over 10 years. A total of 433 esophageal injuries were collected in which: 229 (56.5\%) were cervical, 121 (30.0\%) were thoracic, 69 (17.0\%) were abdominal and $14(3.5 \%)$ were affected multiple esophageal segments. The clinical evidence suggestive of esophageal injury was dysphagia in 29 (7.0\%) and subcutaneous emphysema in 78 (19.0\%). Injury grade distribution according to the American Association of Surgery for Trauma (AAST) classification was: AAST Grade I-III 96\% (367) and AAST Grade IV-V 4\% (16). The overall mortality was $15.5 \%$ for the AAST Grades I-III and $44 \%$ for the AAST Grades IV-V. One hundred and seventy-five patients were managed with immediate surgical intervention and 171 underwent deferred operative management. The surgical interventions were: primary repair in 285 (82\%), resection and esophagostomy in $13(4 \%)$, and simple drainage in 38 (11\%). The most commonly reported complications were: surgical site infection in 27 (8\%), empyema in 25 (7\%), and mediastinitis in $15(4 \%)^{8}$. Makhani et al. reported a series of 327 patients in which the most common mechanism of injury was penetrating trauma secondary to gunshot wounds (48\%). The median ISS was 26.3 and $20.5 \%$ of the patients arrived without vital signs to the emergency room. The overall survival was $70.9 \%{ }^{4}$.

Similarly, we reported a retrospective series of 104 patients with penetrating esophageal trauma from 1992 to 2005, in which 57 (55\%) were by gunshot wounds and 47 (45\%) were by stab wounds. The median ISS was 14.8 (IQR: 4-45) and 65 (63\%) were admitted in hypovolemic shock. The most prevalent injured portion was the cervical in 90 (86\%), followed by the thoracic portion in $11(10 \%)$ and the abdominal portion in $4(4 \%)$. Ninetytwo $(88.4 \%)$ patients showed symptoms upon admission (60\% dysphagia, 35\% dyspnea, 13\% salivary leak, and $4 \%$ abdominal pain). All injuries were managed via primary repair with an additional muscle flap for those located in the cervical (28) or thoracic (9) segments and with a gastric fundus patch for those located in the abdominal portion (4). The most common associated injuries were located in the trachea (25), internal jugular vein (9), subclavian artery (5), spinal cord (12), and lung (5). Also, the most frequently reported complications were: infection (23), esophageal fistula (8), and mediastinitis (3). The overall mortality was $32 \%$ in hemodynamically unstable patients and $3 \%$ in hemodynamically stable patients ${ }^{10}$. 
Table 1. AAST Esophageal Injury Classification

\begin{tabular}{cl}
\hline Grade & Description \\
\hline I & Contusion/Hematoma \\
& Partial-thickness laceration \\
II & Laceration $<50 \%$ of the circumference \\
III & Laceration $>50 \%$ of the circumference \\
IV & Segmental loss or devascularization $<2 \mathrm{~cm}$ \\
V & Segmental loss or devascularization $>2 \mathrm{~cm}$ \\
\hline
\end{tabular}

\section{Initial approach}

Initial management must be directed towards the stabilization of the patient according to the Advanced Trauma Life Support (ATLS) guidelines and following damage control resuscitation principles. Upon arrival, esophageal wounds should be suspected in patients with penetrating cervical trauma, trans-mediastinal injuries, or chest trauma with associated trachea-bronchial tree injuries. All associated vascular injuries with ongoing active surgical bleeding should be addressed initially and controlled before diagnosing and managing the esophageal injury. Only then, the trauma surgeon can direct his or her attention to staging the involved esophageal trauma according to the AAST classification (Table 1).

\section{AAST Esophageal Injury Classification}

The clinical hallmarks of a cervical esophageal injury are pain, dysphagia, dyspnea, stridor, subcutaneous emphysema, hematemesis, hemoptysis, or bleeding from the nasogastric tube. On the other hand, the clinical signs of a wound in the thoracic or abdominal portions are an acute abdomen, cervical crepitus, mediastinal emphysema, and fever ${ }^{7}$.

\section{Surgical Management}

The management strategy proposed for esophageal trauma is outlined in the following algorithm (Figure 1):

STEP 1: Attention should be directed towards identifying all immediate life-threatening injuries following the ABCDE mnemonic according to the ATLS and performing the initial resuscitation maneuvers. Both a common femoral vein and artery lines are placed for intravenous access, blood pressure monitoring, and vigorous damage control resuscitation initiation. If the patient persists with hemodynamic instability despite initial resuscitation maneuvers, the institution's massive transfusion protocol should be activated, and the hemostatic resuscitation and hemodynamic control steps should be followed.

STEP 2: If the patient is hemodynamically stable or a transient responder, a computed tomography of the neck, chest, and abdomen should be performed to determine the extent of the damage and the presence of any other associated injuries. The radiological findings suggestive of an esophageal injury include esophageal wall thickening, pleural effusion, extraluminal air and/or fluid, and wound trajectory near the esophagus. Another useful diagnostic tool to evaluate the extent of the injury is the upper gastrointestinal endoscopy. If you cannot have these resources readily available at your institution, we recommend an esophagram ${ }^{5,7,9,11,12}$. Once the esophageal injury has been identified, orders of nothing per mouth, placement of a nasogastric tube under endoscopic guidance, and intravenous broadspectrum antibiotics should be initiated. The patient should be transferred promptly to the operating room for surgical management. Hemodynamically unstable patients (sustained systolic blood pressure $\leq 70 \mathrm{~mm} \mathrm{Hg}$ ) and non-transient responders should have their common femoral arterial line changed over a guidewire to a femoral sheath, followed by a REBOA in Zone 1 which can be placed either in the operating or emergency room ${ }^{13,14}$. Additionally, the institution's massive transfusion protocol should be activated, and the patient should be transferred immediately to the operating room for direct surgical control. 


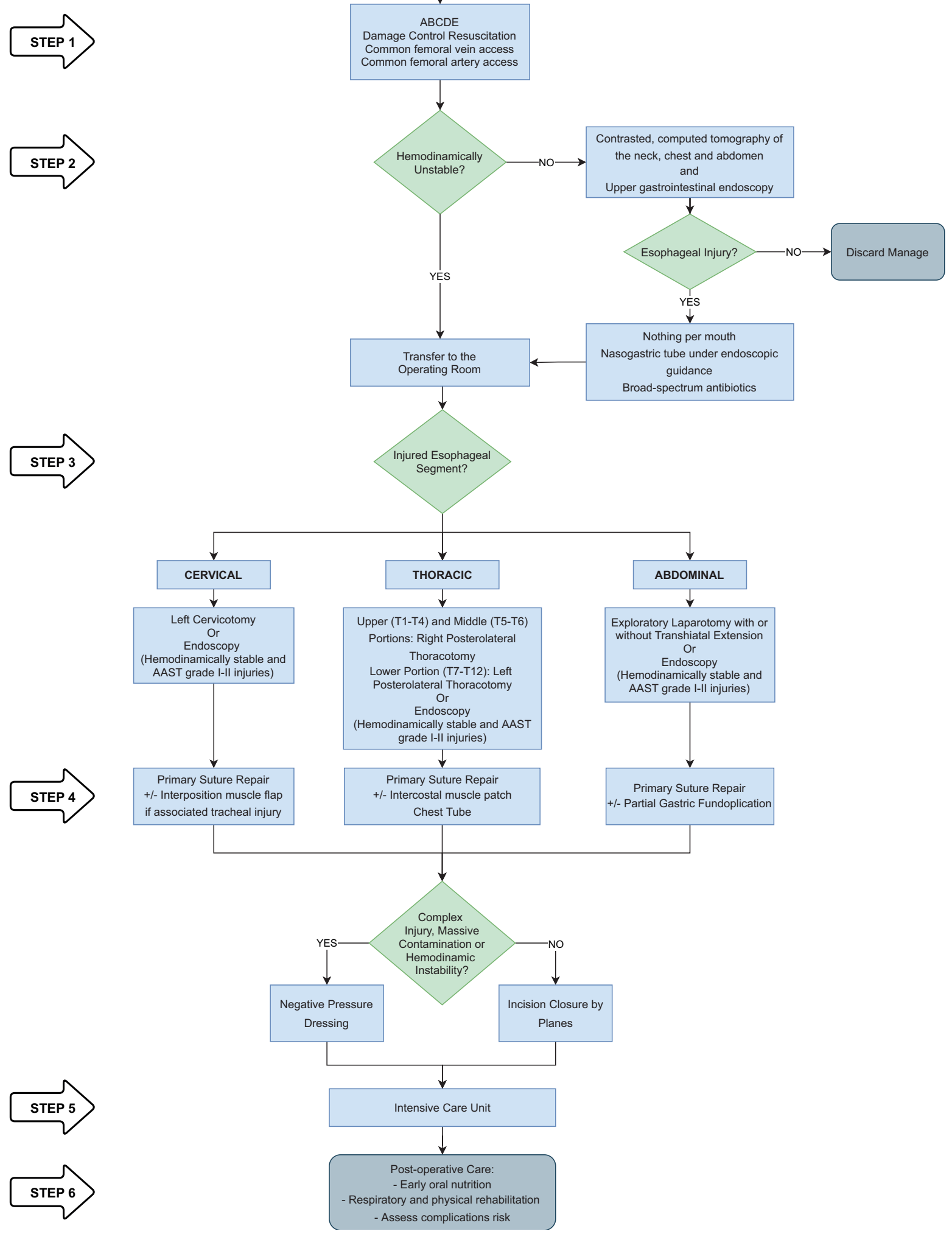

Figure 1. Algorithm for the management of esophageal trauma. 

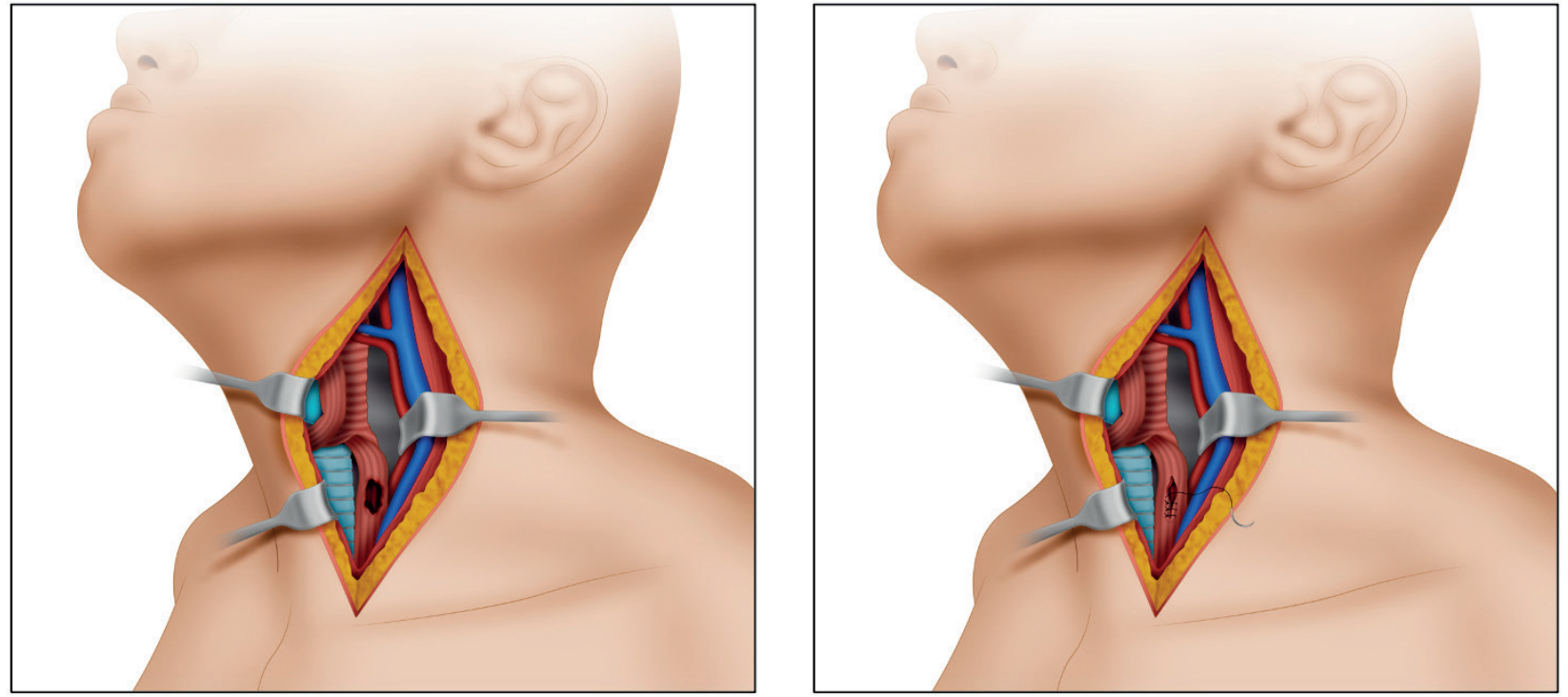

Figure 2. Surgical approach to a cervical esophageal injury. A. The patient's head should be turned towards the right, exposing the anterior triangle of the neck. A left longitudinal incision should follow from the earlobe crease and extending to the sternal notch following the anterior border of the left sternocleidomastoid muscle. B. Primary suture repair is made by using 3-0 PDS absorbable suture as separate transfixing stitches in a single plane. Do not leave any perilesional drainage.

\section{STEP 3 - Surgical Approach:}

- Cervical Esophageal Portion: An endoscopically guided orogastric or nasogastric tube placement should precede the surgical intervention as it helps the surgeon identify the esophagus via palpation. Patients with AAST Grade injuries I or II and who are hemodynamically stable should undergo endoscopic management via primary endoscopic suture repair and/or stent placement when possible ${ }^{13,14}$. If these options are not readily available at your institution, then traditional open surgical management should follow. To this end, the patient's head should be turned towards the right to expose the anterior triangle of the neck. A left longitudinal incision should follow from the earlobe crease and extending to the sternal notch following the anterior border of the left sternocleidomastoid muscle. It is paramount to avoid injuring the left recurrent laryngeal nerve during dissection (Figure 2).

- Thoracic Esophageal Portion: An endoscopically guided orogastric or nasogastric tube placement should precede the surgical intervention as it helps the surgeon identify the esophagus via palpation. Patients with AAST Grade injuries I or II and who are hemodynamically stable should undergo endoscopic management via primary endoscopic suture repair and/or stent placement when possible ${ }^{13,14}$. If these options are not available at your institution, then traditional open or laparoscopic surgical management should follow, depending on the surgeon's expertise. The thoracic esophagus has an upper third (from T1 to T4) which is located along the right thorax, a middle third (from T5 to T6) that lies along the midline, and a lower third (from T7 to T12) which lies towards the left. Therefore, injuries of the upper and middle third should be accessed via a right fourth intercostal posterolateral thoracotomy, while injuries of the lower third should be accessed via a left fourth or fifth intercostal posterolateral thoracotomy. Also, the middle third of the esophagus requires dissection of the mediastinal pleura and elevation of the right bronchus. Iatrogenic vascular injuries to the azygos, the superior vena cava, and/or descending thoracic aorta should be avoided during dissection. However, a thoracoscopic approach can be performed considering the patient's safety and the center and surgeon's expertise (Figure 3). 


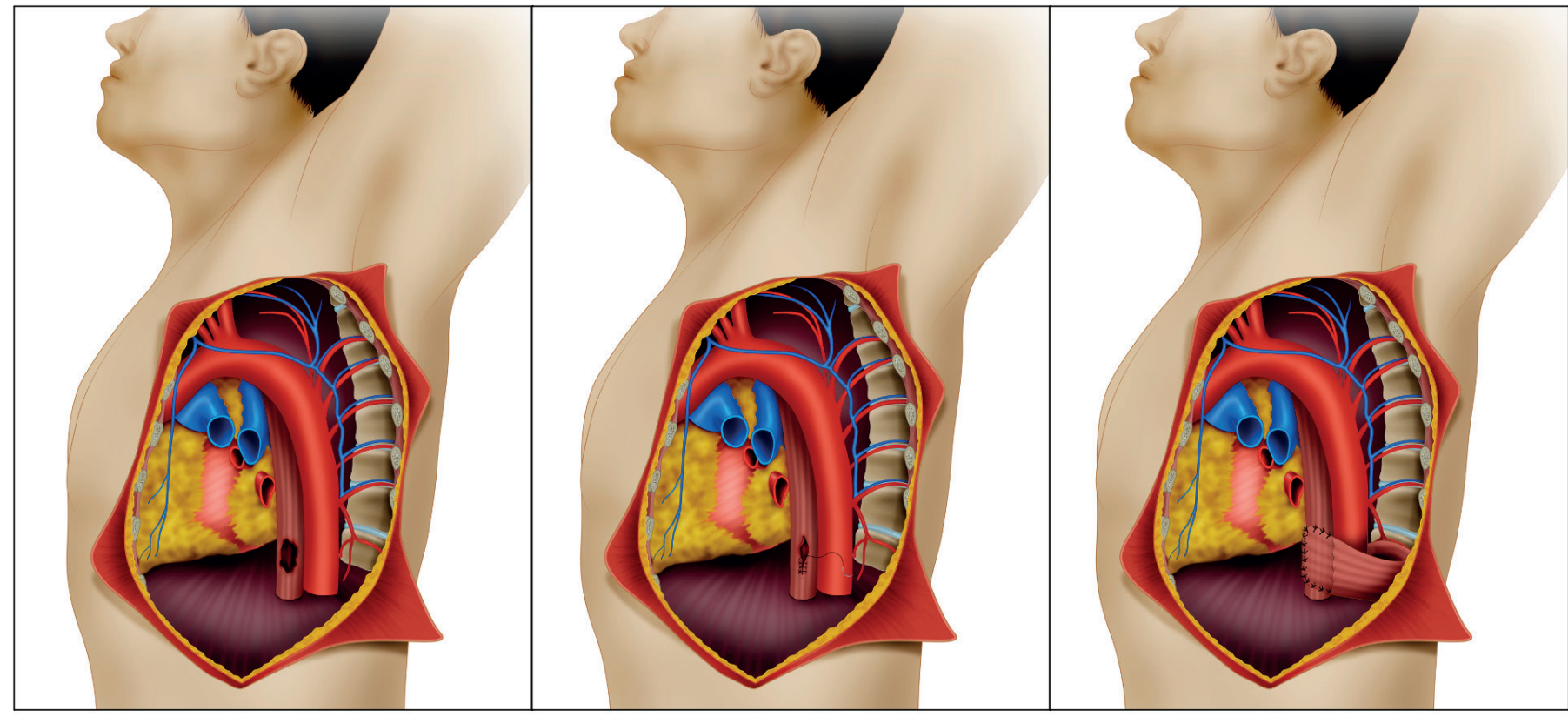

Figure 3. Surgical approach to an inferior thoracic esophageal injury. A. Inferior thoracic esophageal injury. These injuries should be accessed via a left fourth or fifth intercostal posterolateral thoracotomy. B. Primary suture repair is made by using 3-0 PDS absorbable sutures as separate stitches in a single plane. C. The repair should be reinforced with a viable and well-perfused intercostal muscle patch. Finally, a chest tube should be placed and, if possible, the incision should be closed by planes.

- Abdominal Esophageal Portion: An endoscopically guided orogastric or nasogastric tube placement should precede the surgical intervention as it helps the surgeon identify the esophagus via palpation. Patients with AAST Grade injuries I or II and who are hemodynamically stable should undergo endoscopic management via primary endoscopic suture repair and/or stent placement when possible. If these options are not readily available at your institution, then traditional open surgical management should follow. These injuries can be accessed and repaired via a laparotomy and may require a transhiatal extension to achieve proximal control of the injury.

STEP 4 - Injury Management: The magnitude and extension of the esophageal injury should be determined following the AAST grading classification.

- Cervical Esophageal Portion: Primary repair should follow appropriate debridement of all necrotic tissue (Figure 2). Also, an associated tracheal injury should be ruled out and, if present, should undergo primary repair followed by an interposition muscle flap between both structures to decrease the possibility of a tracheoesophageal fistula formation. Incision closure should be performed in most cases, but if the injury is complex and/or more than 24 hours old, damage control principles should be considered, and a negative pressure dressing should be applied.

- Thoracic Esophageal Portion: Primary repair should follow appropriate debridement of all necrotic tissue. The repair should be reinforced with a viable and well-perfused intercostal muscle patch (Figure 3). A chest tube should be placed, and the incision closed by planes. Incision closure should be performed in most cases, but if the injury is complex and/or more than 24 hours old, damage control principles should be considered, and a negative pressure dressing should be applied.

- Abdominal Esophageal Portion: Primary repair should follow appropriate debridement of all necrotic tissue. The repair should be reinforced with partial gastric fundoplication. Incision closure should be performed in most cases, but if the injury is complex and/or more than 24 hours old, damage control principles should be considered, and a negative pressure dressing should be applied. 
STEP 5: The patient should be transferred to the intensive care unit (ICU) for lethal diamond correction (acidosis, hypothermia, coagulopathy, and hypocalcemia). Once obtained, the patient should be transferred back to the operating room for definitive wound closure.

STEP 6: If injuries are fully repaired without complications, and the patient presents an appropriate clinical evolution, early oral feeding and intensive respiratory/physical rehabilitation may be initiated between the second and third day. Otherwise, close clinical surveillance should be continued and a postoperative follow-up esophagram should be performed between the $7^{\text {th }}$ and $10^{\text {th }}$ postoperative days to rule out leaks. If a leak is visualized, then appropriate open or percutaneous drainage of the injury site should be guaranteed. Otherwise, oral feeding can be initiated, and follow-up can be continued on an outpatient basis. Between the 3rd and sixth months, endoscopic control is suggested to rule out long-term complications such as esophageal stenosis.

\section{Complications}

The main complications associated with esophageal injuries are wound infections, abscess formation, suture line dehiscence, esophageal-cutaneous and trachea-esophageal fistulas. Systemic complications include mediastinitis, pneumonia, empyema, sepsis, and death. Asensio et al., reported a complication rate of less than $10 \%$ and determined that the risk factors associated with them were delayed surgical management, AAST Grades $>$ II and those who underwent esophagostomy ${ }^{8}$. Therefore, we recommend that primary surgical repair be the procedure of choice and the patient should be managed closely in the ICU postoperatively ${ }^{12}$.

Complications that the surgical team should avoid in the short term are repair leakage, infection, or fistulas. In addition, poor clinical evolution, fever, or subcutaneous emphysema should alarm the surgeon. If there are signs that raise suspicion of complications, the patient should be transferred to the operating room, the wound should be drained, and a negative pressure dressing should be placed. It is not recommended to perform esophagostomas in the first surgical time.

\section{Conclusion}

The strategy of damage control surgery for esophageal injuries should always be, when possible, primary repair, endoscopic nasogastric tube placement, and close postoperative care in the intensive care unit.

\section{References}

1. Asensio JA, Berne J, Demetriades D, Murray J, Gomez H, Falabella A, et al. Penetrating esophageal injuries: Time interval of safety for preoperative evaluation - How long is safe? J Trauma. 1997; 43: 319-24. Doi: 10.1097/00005373-199708000-00018.

2. Griffiths EA, Yap N, Poulter J, Hendrickse MT, Khurshid M. Thirty-four cases of esophageal perforation: The experience of a district general hospital in the UK. Dis Esophagus. 2009; 22: 616-25. Doi: 10.1111/j.14422050.2009.00959.x.

3. Vogel SB, Rout WR, Martin TD, Abbitt PL, Livingstone AS, LoCicero J, et al. Esophageal perforation in adults: Aggressive, conservative treatment lowers morbidity and mortality. Ann Surg. 2005; 241: 1016-23. Doi: 10.1097/01.sla.0000164183.91898.74.

4. Makhani M, Midani D, Goldberg A, Friedenberg FK. Pathogenesis and outcomes of traumatic injuries of the esophagus. Dis Esophagus. 2014; 27: 630-6. Doi: 10.1111/dote.12132.

5. Young CA, Menias CO, Bhalla S, Prasad SR. CT features of esophageal emergencies. Radiographics. 2008; 28: 1541-53. Doi: 10.1148/rg.286085520. 
6. Chirica M, Champault A, Dray X, Sulpice L, Munoz-Bongrand N, Sarfati E, et al. Esophageal perforations. J Visc Surg. 2010; 147: e117-28. Doi: 10.1016/j.jviscsurg.2010.08.003.

7. Petrone P, Kassimi K, Jiménez-Gómez M, Betancourt A, Axelrad A, Marini CP. Management of esophageal injuries secondary to trauma. Injury. 2017; 48: 1735-42. Doi: 10.1016/j.injury.2017.06.012.

8. Asensio JA, Chahwan S, Forno W, MacKersie R, Wall M, Lake J, et al. Penetrating esophageal injuries: Multicenter study of the American Association for the Surgery of Trauma. J Trauma. 2001; 50: 289-96. Doi: 10.1097/00005373-200102000-00015.

9. Fadoo F, Ruiz DE, Dawn SK, Webb WR, Gotway MB. Helical CT Esophagography for the evaluation of suspected esophageal perforation or rupture. Am J Roentgenol. 2004; 182: 1177-9. Doi: 10.2214/ ajr.182.5.1821177.

10. Millan M, Garcia AF, Ferrada R. Trauma Esofágico: Reporte de 104 casos. Panam J Trauma. 2006; 13: 72-3.

11. Arantes V, Campolina C, Valerio SH, De Sa RN, Toledo C, Ferrari TA, et al. Flexible esophagoscopy as a diagnostic tool for traumatic esophageal injuries. J Trauma. 2009; 66: 1677-82. Doi: 10.1097/ TA.0b013e31818c1564.

12. Biffl WL, Moore EE, Feliciano DV, Albrecht RA, Croce M, Karmy-Jones R, et al. Western trauma association critical decisions in trauma: diagnosis and management of esophageal injuries. J Trauma Acute Care Surg. 2015; 79: 1089-95. Doi: 10.1097/TA.0000000000000772.

13. Ordoñez CA, Rodríguez F, Orlas CP, Parra MW, Caicedo Y, Guzmán M, et al. The critical threshold value of systolic blood pressure for aortic occlusion in trauma patients in profound hemorrhagic shock. J Trauma Acute Care Surg. 2020; 89: 1107-13. Doi: 10.1097/TA.0000000000002935.

14. Ordoñez CA, Parra MW, Caicedo Y, Padilla N, Rodríguez-Holguín F, Serna JJ, et al. REBOA as a new damage control component in hemodynamically unstable noncompressible torso hemorrhage patients. Colomb Med (Cali). 2020;51(4): e4064506. Doi: 10.25100/cm.v51i4.4506 